\title{
Artificial Intelligent Technique based Double-Frequency Analysis on a Single-Phase Grid-connected Inverter
}

\author{
Maheeth $\mathrm{P} \mathrm{V} \mathrm{S}^{1, *}$, Srividya Devi $\mathrm{P}^{2}$, Sirisha $\mathrm{P}^{3}$ \\ ${ }^{1} \mathrm{P}$ G Scholar, EEE Department, GRIET, Hyderabad \\ ${ }^{2}$ Associate Professor, EEE Department, GRIET, Hyderabad \\ ${ }^{3}$ Assistant Professor, EEE Department, GRIET, Hyderabad
}

\begin{abstract}
Now a days more power losses can be seen in grid connected inverter. In order to reduce that double frequency in single phase grid inverter with Artificial Intelligent based fuzzy control is implemented. The inverter has two operating units High Frequency Unit (HFU) and Low Frequency Unit (LFU), low frequency reduce switching losses and high frequency suppress the symphonious currents. The fuzzy logic method expected towards deliver high yield, low total symphonious distortion, rapid response. Finally Total Symphonious Distortion (THD) contrasted among fuzzy including Integral controls (PI). The results are validated by using MATLAB/Simulink.
\end{abstract}

\section{Introduction}

The DC/AC Converter is always an important part of grid connected system [1]. Many switching symphonious are there in grid side current, to reduce that we will use passive filters like L or LCL filters to the grid [2-4]. The L filter has less complex structure, more reliability also have more inductance value and it has high voltage drop so it will reduce the system performance, instead of using L filter, LCL filter can be tried it has good capacity to reduce higher order symphonious[5], but it has the disadvantage of resonance. There are many new developments in semiconductor devices, that are widely used in many applications. These help to reduce the switching symphonious in a good way. Using these semiconductor devices in low and HFUs may add up some cost but the quality of the current will be good. The purpose of using controllers is when a system cannot fulfil the needs, then some variables will be used to achieve the wanted results.

The PLL (Phase Locked Loop) [6-8] is a closed loop system will generate an output frequency in relation with Phase and Magnitude of an input frequency it consists of variable oscillator and phase detector and feedback loop, these three are common parts of it. Through this process it will protect the grid from symphonious currents.

For controlling the inverters mostly PI controllers are used but to solve the mathematical model or transfer function will be complex to obtain that problem Fuzzy can be used. We can observe the importance of Fuzzy logic not only in computer science domain but also developing in industrial side [9-11], rocket engineering, and many domains. Fuzzy logic is a rule based controller, if any system uses fuzzy logic then it is called fuzzy model. We can observe some important applications of fuzzy in railway system, factories, air conditioner, camera control technique, in hospitals also while checking diagnostic procedure and diagnoses radiology and prostate cancer the machinery is installed with some of these fuzzy logics, washing machine controlling, vacuum cleaner, subway design for trains, it can tell the altitude of plane, range of it as this fuzzy is implemented in aerospace technology, traffic signal [1214]. It has a good problem solving technique in the way its demand is increasing. Its decision making happens on three steps fuzzification, interfacing, and defuzzification. We can use this fuzzy in power electronics applications like controlling the speed of the motor, in electrical vehicles testing, this adds up a benefit to the systems. when compared to PI controllers this will be more beneficial because it thinks like human interface, it is faster and there is no mathematical approach to the fuzzy logic, it will show the results in the $[0,1]$ format either the result produced will be false or true, it does not a give a situation in between them, and a membership graph will be seen with error and change in error it will relate those two graphs with rules that fuzzy had included in it. Fuzzy will simplify the data for itself to provide a valid reason to achieve the desirable output. A double frequency inverter proposed [15-19] will have two inverters used in different frequencies and achieves

\footnotetext{
* Corresponding author: maheeth333@gmail.com
} 
good performance and results. Here it will deal with two frequencies that are on either side of the grid system, doing two different functions [20-23]. In this paper the results Total Symphonious Distortion for the proposed converter using PI and Fuzzy Logic control are shown.

\section{Proposed inverter}

The inverter shown in Fig. 1 depicts proposed inverter's topography. It has LFU and HFU. These two units will have separate DC voltage of grid, Vdc1 and Vdc2 are low-frequency and high-frequency voltages. The inductances for two units will be La and Lb. The LFU will operate as inverter mode where electric energy goes to power grid. The HFU operates as rectifier mode which will eliminate symphonious currents came from LFU. It has four diodes and thyristors in low and HFUs. Grid voltage is connected across low and HFUs, VINV is the low frequency output voltage and VREC is high frequency output voltage. In low frequency IGBT are present and in high frequency MOSFET are present.

$$
\mathrm{V}_{\mathrm{La}}=\mathrm{V}_{\mathrm{INV}}-\mathrm{V}_{\mathrm{g}}
$$

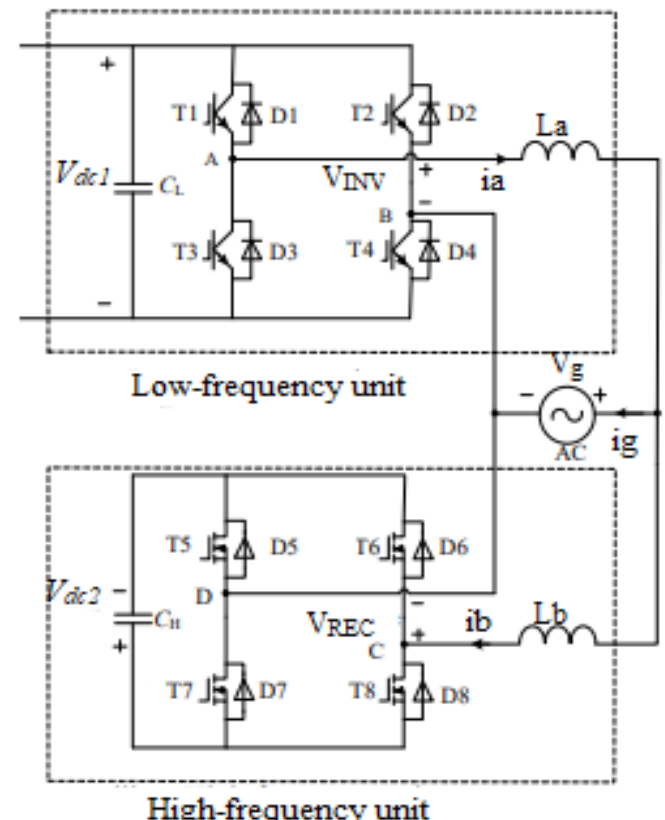

Fig 1. Low and High frequency Unit of Inverter

The fundamental component and symphonious component of $\mathrm{L}_{\mathrm{a}}$ are $\mathrm{V}_{\mathrm{La} \_}$and $\mathrm{V}_{\mathrm{La} \_ \text {h }}$.

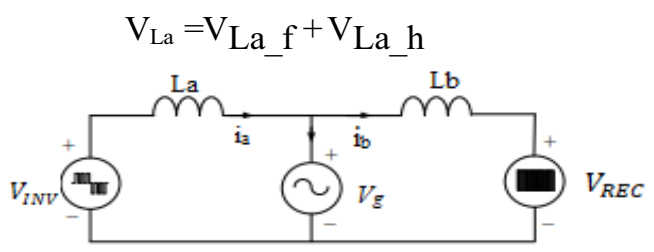

Fig 2. Similar circuit model of implemented inverter
The fundamental and symphonious component of ia in steady state are ia $f$ and ia $h$.. These two are produced by VLa_f and VLa_h. respectively. Thus,

$$
\begin{gathered}
\mathrm{i}_{\mathrm{a}}=\mathrm{i}_{\mathrm{a}_{-} \mathrm{f}}+\mathrm{i}_{\mathrm{a}_{-} \mathrm{h}} \\
\mathrm{V}_{\mathrm{La} \_\mathrm{f}}=\mathrm{L}_{\mathrm{a}} \\
\mathrm{V}_{\mathrm{La} \_\mathrm{h}}=\mathrm{L}_{\mathrm{a}} \frac{d \mathrm{dia}_{-} \mathrm{h}}{d t}
\end{gathered}
$$

error of SteadyState for current is ignored and $i_{a_{-} f}$ is considered as $i^{*}$ of the grid current,

$$
\mathrm{V}_{\mathrm{La} \_\mathrm{f}}=\mathrm{L}_{\mathrm{a}} \frac{d \mathrm{i}_{g}^{*}}{d \mathrm{t}}
$$

Therefore, symphonious current 1 h of the LFU can be calculated as

$\mathrm{i}_{\mathrm{a}_{-} \mathrm{h}}=\int_{0}^{t} \frac{v_{\mathrm{La}} \mathrm{h}}{V_{L a}} \mathrm{dt}=\int_{0}^{t} \frac{V_{I N V}-V_{g}-\mathrm{La}-\frac{d i_{g}^{*}}{d t}}{L a} \mathrm{dt}$

As the switching frequency will be higher in HFU they are ignored, $i_{b}$ can be calculated from the average of $\mathrm{V}_{\mathrm{REC}}$ in a high switching frequency.

$$
\mathrm{i}_{\mathrm{b}}=\int_{0}^{t} \frac{V_{L_{b}}}{L_{b}} d t=\int_{0}^{t} \frac{V_{g}-V_{R E C}}{L_{b}} \mathrm{dt}
$$

$$
\text { From Fig. } 2 \mathrm{i}_{\mathrm{g}}=\mathrm{i}_{\mathrm{a}}-\mathrm{i}_{\mathrm{b}}
$$

By substituting (3),(7),(8) into (9) we get $i_{g}$

$$
\begin{gathered}
\mathrm{ig}_{\mathrm{g}}=\mathrm{i}_{\mathrm{a}_{-} \mathrm{f}}+\mathrm{i}_{\mathrm{b}} \mathrm{h}-\mathrm{ib}_{\mathrm{b}} \\
=\mathrm{i}_{\mathrm{a}_{-} \mathrm{f}}+\int_{0}^{t} \frac{V_{I N V}-V_{g}-\mathrm{La}-\frac{d \mathrm{i}_{g}^{\bullet}}{d t}}{L a} \mathrm{dt}-\int_{0}^{t} \frac{V_{g}-V_{R E C}}{L_{b}} d t
\end{gathered}
$$

Observing from (11) if,

$$
V_{R E C}=V_{g}+\frac{L_{b}}{L_{a}}\left(+V_{g}+L_{a} \frac{d i_{g}^{*}}{d t}-V_{l N V}\right)
$$

Two integral terms are eliminated from (10) the grid current contains only ia $f$ from LFU, then voltage recompense $\mathrm{VCH}$ is given by

$$
\mathrm{U}_{\mathrm{CH}}=\frac{V_{R E C}}{V_{d c 2}}=\frac{V_{g}+\frac{L_{h}}{L_{a}}\left(+V_{g}+L_{a} \frac{d i_{g}^{\mathrm{g}}}{d t}-V_{l N V}\right)}{V_{d c 2}}
$$

\section{The design of filter inductor}

The inductance La value will be obtained from the ratio of VLa_f to the amplitude of Vg is taken as 0.2

$$
\mathrm{L}_{\mathrm{a}}=\frac{V_{L_{a f} M}}{2 \pi f_{1} i_{M}}=\frac{0.2 V_{G M}}{2 \pi f_{1} i_{M}}
$$

Where $\mathrm{fl}$ is the frequency for voltage of grid, $\mathrm{Vg}$ is the amplitude for voltage of grid, and IM is the LFU current amplitude. 
The inductor $\mathrm{Lb}$ function is to filter the symphonious at HFU so the capability to reduce the amplitude of a signal at the switching frequency $f_{s z}$ is given below

$$
20 \lg _{2 \pi f_{s 2} 2_{h}} \geq-50 \mathrm{~dB}
$$

Value of $\mathrm{L}_{\mathrm{b}}$ can be calculated by

$$
\mathrm{L}_{\mathrm{b}}=\frac{10^{2.5}}{2 \pi f_{s 2}}
$$

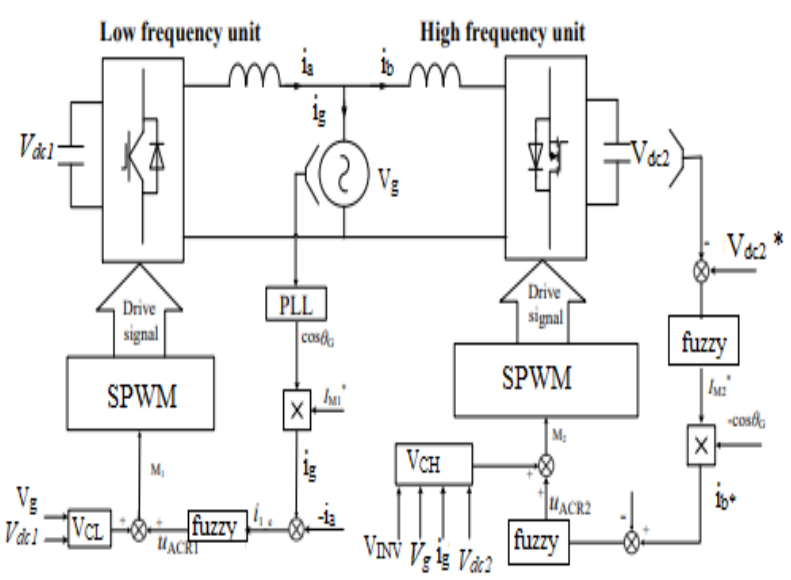

Fig 3. Block diagram of Fuzzified Double Frequency Single Phase Inverter

\section{Control system of the proposed inverter}

From PLL at inverter side voltage Vg has a Phase angle $\theta$, and the reference current amplitude will be $I_{M}^{*}$, and ia is compared with the reference current from grid side $i_{g}^{*}$, from Fig 3. The error signal from the current is i1_e is sent to fuzzy. Grid voltage recompense VCL is equal to $\mathrm{Vg} / \mathrm{Vdc} 1$ which will reduce the effect of $\mathrm{Vg}$. The adding of VCL and the end current of regulator will be the transition signal M1. The aim of the HFU is to maintain the DC voltage same Vdc2 of the system and produce current $\mathrm{ib}$ to discharge the symphonious currents of ia. ${ }^{i} b$ is known as reference current value and $i_{2}^{*}$ will be solved by phase angle ${ }^{\theta}$, current amplitude reference $I_{M 2}^{*}$. The error of ig and $i_{g}^{*}$ is ig e and $i_{b}^{*}$ as reference current value of loop. The voltage recompense $\mathrm{VCH}$ eliminates the symphonious component ia_h of LFU.

$$
V_{C H}=\frac{\left(1+\frac{L_{b}}{L_{a}}\right)+L_{b} \frac{d \hat{l}_{g}^{*}}{d t}-\frac{L_{h}}{L_{g}} V_{V N V}}{V_{d c 2}}
$$

The standard of the LFU drive signal and the theory of single polar transition is shown below
$V_{I N V}=\left\{\begin{array}{c}V_{d c 1} \\ -V_{d c 1} \\ 0\end{array}\right.$

$$
\begin{gathered}
T 1(0 n), T 4(o n) \\
T 2(o n), T 3(o n) \\
\text { other cases }
\end{gathered}
$$

The transition signal M2 of the HFU is the sum of VCH and fuzzy output. The HFU works in the rectifier mode. So, the DC capacitor voltage has to be adjusted to produce stabilize sufficient current to reduce the symphonious of the LFU. The expression for voltage of the grid and reference current is shown below

$$
\begin{gathered}
\mathrm{V}_{\mathrm{g}}(\mathrm{t})=\mathrm{V}_{\mathrm{GM}} \cos (\omega t) \\
i_{g}^{*}=I_{M}^{*} \cos (\omega t+\theta)
\end{gathered}
$$

Here $\omega$ is the angular frequency of the $\mathrm{Vg}, \theta$ is the phase difference of the $\mathrm{Vg}$ and the $i_{g}^{*}$. Substituting (18) and (19) into (11), VREC can be calculated as

$$
V_{R E C}(t)=V_{m} \cos (\omega t+\varphi)-\frac{L_{b}}{L_{a}} \mathrm{~V}_{\mathrm{INV}}
$$

Where

$$
\mathrm{V}_{\mathrm{m}}=\sqrt{\left[\left(1+\frac{L_{b}}{L_{a}}\right) V_{g m}+L_{b} \omega I_{M}^{*} \sin \theta\right]^{2}}+\left(L_{b} \omega I_{M}^{*} \cos \theta\right)^{2}
$$

$$
\varphi=\tan ^{-1} \frac{\left(L_{b} \omega l_{M}^{*} \cos \theta\right)}{\left(1+\frac{L_{h}}{L_{a}}\right) V_{g m}+L_{b} \omega l_{M}^{*} \sin \theta}
$$

and $I_{M}^{*}$ of the LFU. If SPWM is used in the LFU then, VREC is a square wave having amplitude Vdc1, fs1 (frequency), and its polarity also same as $\mathrm{Vg}$. The maximum possible value of $\operatorname{VREC}(\mathrm{t})$ will be $\mathrm{Vm}, \mathrm{Vdc} 1$ and inductor ratio ${ }^{\frac{L_{a}}{L_{h}}}$. $\left|V R E C \_m\right|$ has two conditions now,

$\left|\mathrm{V}_{\text {REC_m } \mathrm{m}}\right|=\left\{\begin{array}{cl}V_{m} & V_{m} \geq \sin \varphi+\frac{L_{b}}{L_{a}} V_{d c 1} \\ V_{m} \sin \varphi+\frac{L_{b}}{L_{a}} V_{d c 1} & V_{m}<V_{m} \sin \varphi+\frac{L_{b}}{L_{a}} V_{d c 1}\end{array}\right.$

As HFU working in the rectifier mode, Vdc2 needs a good and stable design so that it can observe good results and restrict the saturation of the regulator.

$$
V_{d c 2}=\gamma\left|V_{R E C_{-}} m\right|
$$

\section{Fuzzy Logic Controller}

Fuzzy which is an Artificial Intelligent (AI) technique is utilized effectively in different types of control applications. Pretty much every purchaser item has some sort of fluffy control. Controlling the room temperature with a forced air system, hostile to stopping mechanisms in vehicles, traffic signal control, clothes washers, etc are 
a few models. We will observe these things in daily life. We can utilize human information and experience to plan a regulator by utilizing fluffy rationale for control. The fuzzy control rules, or IF-THEN standards, are the awesome planning a control framework. Fuzzifier's responsibility is to change the fresh information esteems into fluffy ones. Fuzzy Knowledge the data pretty much every one of the info yield fluffy connections is put away in the base. It additionally indicates the fluffy principal base's information factors and the plant levelled out's yield factors. Fuzzy Rule Base It stores data about the space interaction's movement. Derivation Engine It fills in as the part for any FLC. Basically, it performs rough thinking to display human choices. Defuzzifier is to change over fluffy qualities acquired from the fluffy deduction motor into fresh qualities. PWM-controlled two level generator is used for carrier based two level PWM method where the fuzzy generated output will pass through it and current reference amplitude will be added to that. Fig 4 is the membership function of the fuzzy having two inputs.

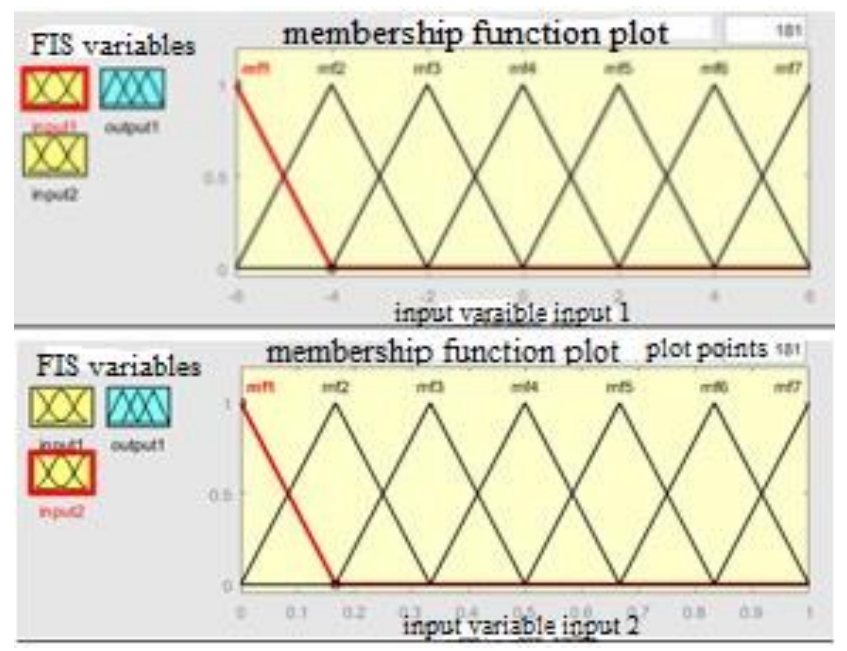

Fig 4. Triangular Membership function for change in-error.

Here we compare the Total Symphonious distortion of low and high frequency current using two controllers. As we can see from Fig 5 the THD of low frequency current is $9.67 \%$ and grid current is $3.80 \%$ measured through Fast Fourier Transform (FFT), It will provide the discrete Fourier in an efficient manner and will get the accurate results based on possible conditions. This type of representation carries information about magnitude and phase at each frequency, in this paper we took the frequency difference as $500 \mathrm{~Hz}$. For every frequency we took the magnitude, this magnitude will tell the power of frequency components.

\section{Simulation Results and Discussions}

While using PI we got magnitude Fig 5 max of 0.08 between the range $(0,100) \mathrm{Hz}$ fir current i1, when fuzzy is used magnitude of 0.03 between the range of $(0,100)$ $\mathrm{Hz}$ in Fig 7 so the symphonious frequency strength is reduced after using fuzzy. The same results for the current ig in Fig 6 the magnitude is at 0.1 between the range $(0,100) \mathrm{Hz}$, in Fig 8 the symphonious currents strength decreased to 0.045 in the same range, so the fuzzy implementation helped to reduce the bad currents and helped system to stabilize well.

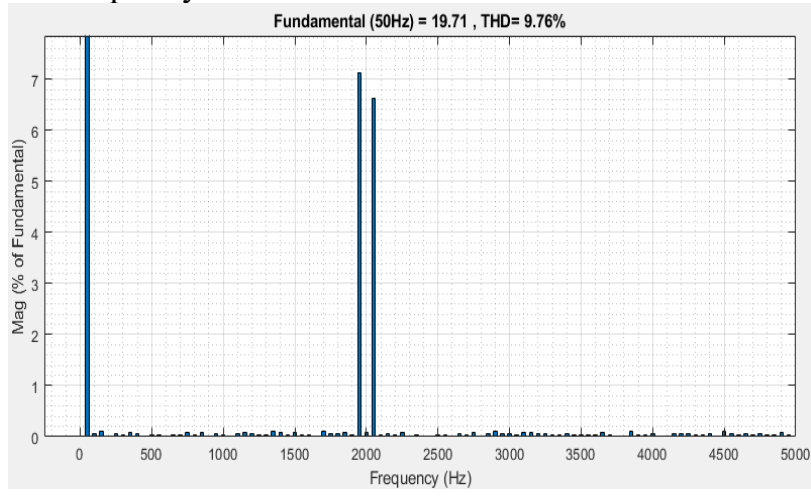

Fig 5. FFT analysis of Current $i_{1}$ using PI Controller

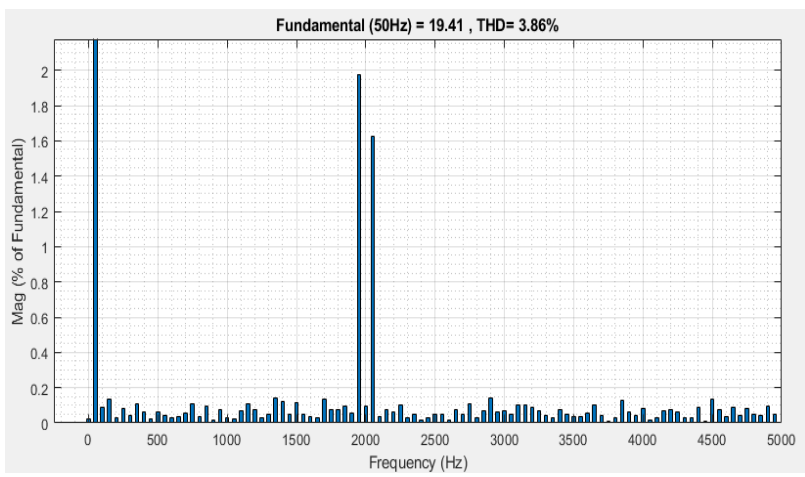

Fig 6. FFT analysis of current $i_{g}$ using PI Controller

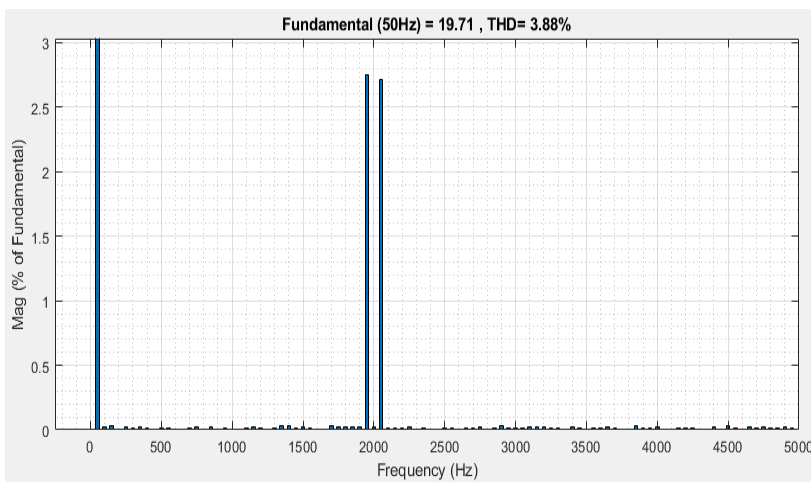

Fig 7. FFT analysis of current $i_{1}$ using fuzzy Controller

After using fuzzy control by replacing PI, we can see the results from Fig 7 and 8 THD of low frequency current is $3.89 \%$ and grid current is $1.47 \%$. It can clearly observe the reduction of symphonious currents in both the results, and the waveforms of grid voltage, grid currents, and output voltages from HFU and LFU are mentioned here. The waveforms obtained are Fig 9 Waveform of Vdc2 at HFU is the output voltage, Fig 10 waveform of current i2 at HFU this waveform resulted after the current passed through fuzzy, Fig 11 waveform of il at LFU resulted when il passed through PLL and 
passed through fuzzy, Fig 12 waveform of grid current ig, Fig 13 waveform of grid voltage vg.

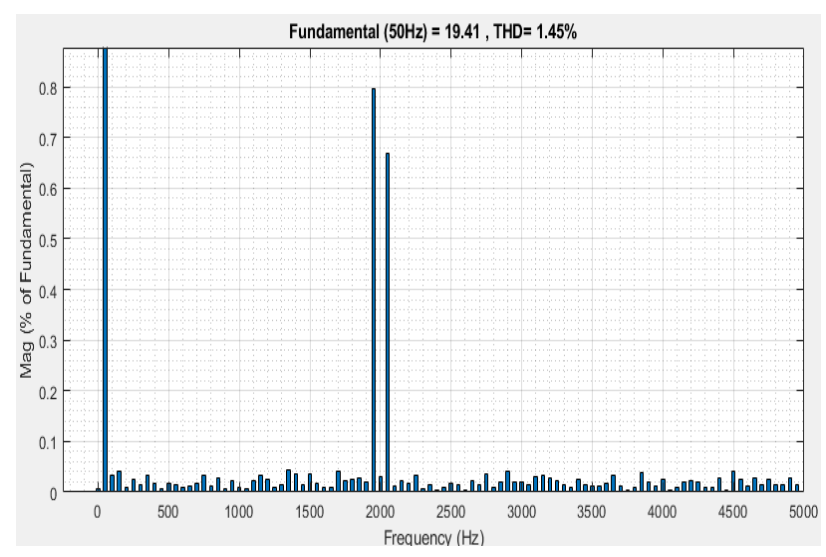

Fig 8. FFT analysis of current ig using Fuzzy Controller

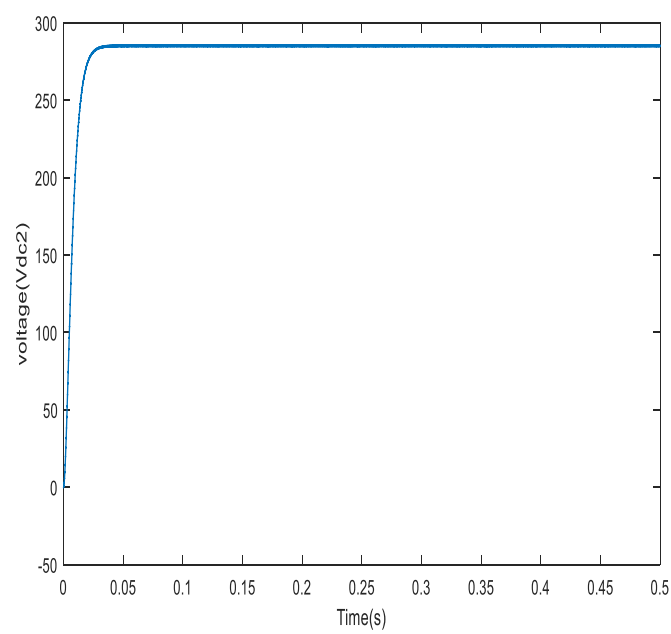

Fig 9. Waveform showing $\mathrm{Vdc}_{2}$ at High Frequency Unit (HFU)

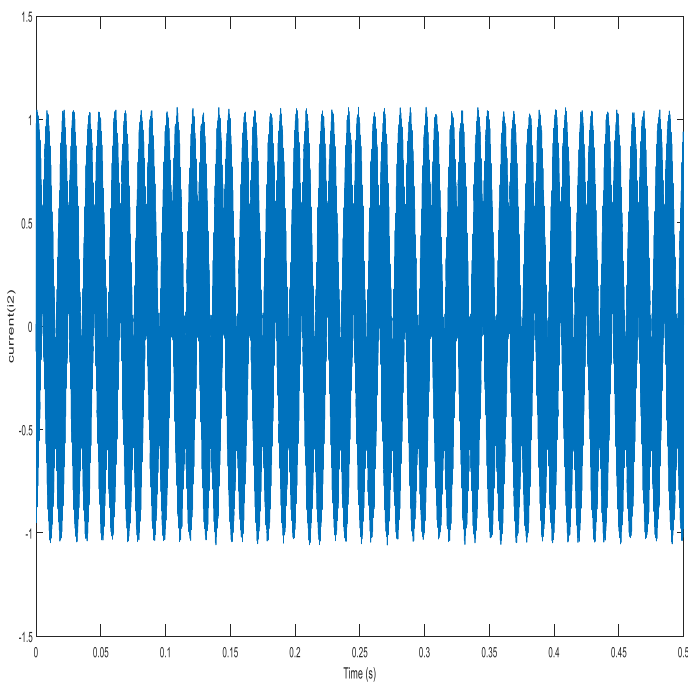

Fig 10. Waveform of Current $i_{2}$ at $\mathrm{HFU}$

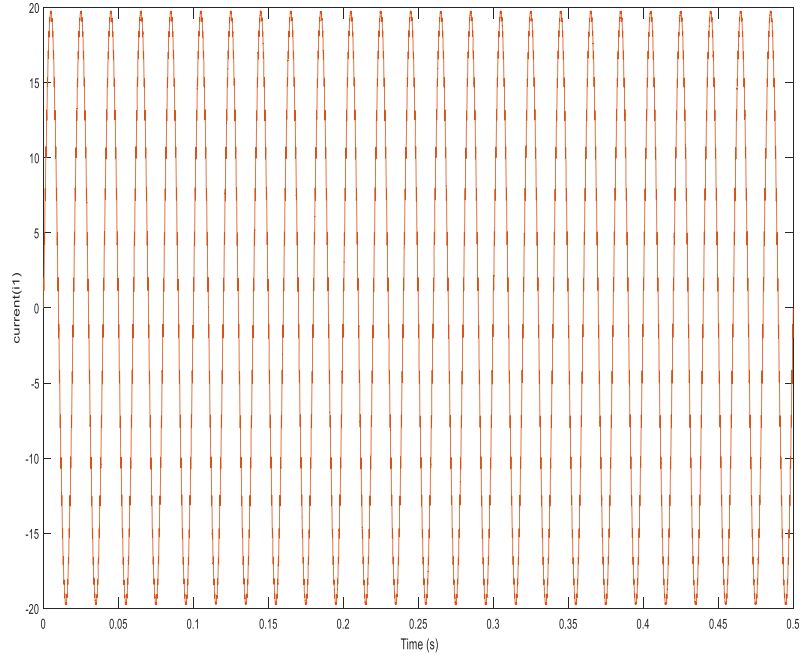

Fig 11. Waveform of current $i_{1}$ at LFU

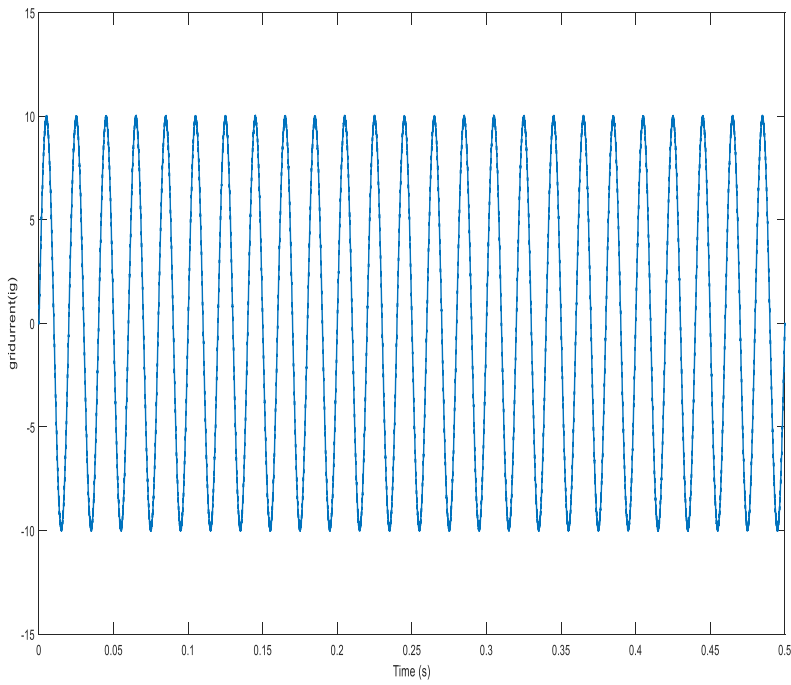

Fig 12. Waveform of grid current (ig)

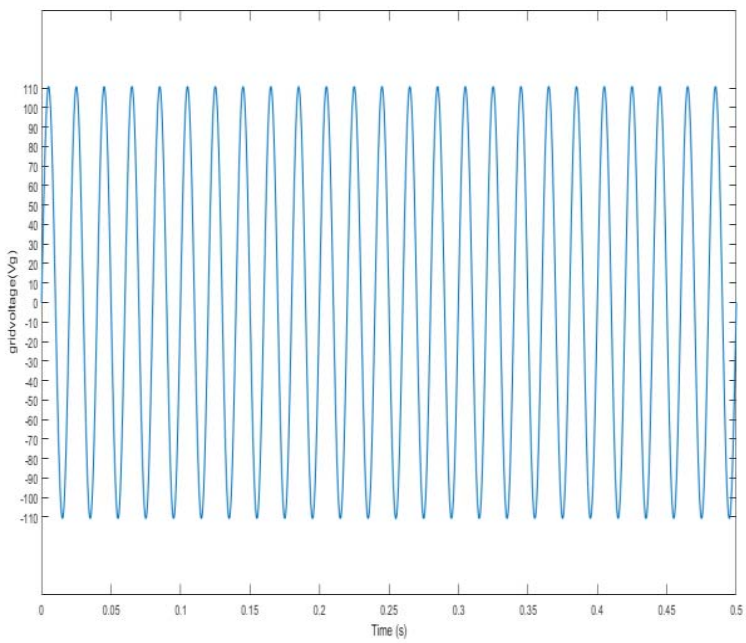

Fig 13. Waveform of grid voltage (Vg) 


\section{Conclusions}

In this paper the difference of results between using PI controller and Fuzzy logic results are shown through FFT analysis. The main aim of this paper is to reduce the THD of LFU current and grid current and the current symphonious are eliminated by using SPWM technique. Hence Fuzzy logic meet quick reaction including least possible THD, results were analysed through MATLAB Simulink.

\section{References}

1. B. K, V. G. Agelidis and J. Pou, IEEE Trans. on Sus Egy, 5, 1297 (2014)

2. R.Fantino A, Busada et. al., IEEE Trans. on PE, 33, 793 (2018)

3. M.Sanatkar, M. Monfared, IET PE, 9, 1971 (2016)

4. Y. Jiao and F. C. Lee, IEEE Trans on Power Electronics, 32, (2017)

5. Z. Liu, H. Wu, Y. Liu, J. Ji, W. Wu and F. Blaabjerg, IET PE, 10, 151 (2017)

6. Saeed Golestan, Ana vidal, Franciso D Freijedo, josep M, Jsus Doval-gandoy, IEEE Trans on PE, 31, (2016)

7. Jung Mao-Lin, Ching Yuan Yang, IEEE Trans on CS, 62, (2015)

8. T.Musch, M.Gerding, B.Schiek, IEEE Trans on Instrumentation and Measurement, 54, (2005)

9. S.Dick; IEEE Trans on Fuzzy systems, 13, 3 (2005)

10. Zadeh, Information and control, 8, 338 (1965)

11. A,Soetedjo, Yusuf Ismail, Choirul Saleh, ICSGSC 2nd International Conf (2018)

12. Juntao Fei, Yunkai Zhu, ICMA (2017)

13. Slash Hafsi, Mehdi dhaoui, Lassad smita, ICGECS, (2017)

14. T. Tari, L.T. Koczy, C, Gaspar, J.Hontvari. IEEE conf on Fuzzy systems, (2006)

15. Liyong Ynag, Aoyu Chang, Shuo liu, Yuan Wang, IEEE Conf on PE, (2019)

16. M. Lutze and M. Kopf, EPE'16 ECCE Europe, Karlsruhe, (2016)

17. A. Barrado, R. Vazquez, E. Olias, A. Lazaro and J. Pleite, IEEE Trans on PE, 19, 1003 (2004)

18. A. A. Rockhill, M. Liserre, R. Teodorescu and P. Rodriguez, IEEE Trans on IE, 58, 1205 (2011)

19. X. Du, L. Zhou and H. Tai, IEEE Trans on IE, 56, 1690 (2009)

20. Sridevi, J., Amarnath, J., Govinda Rao, G., International Review on Modelling and Simulations , 4, 2485 (2011)

21. Sridevi, J., Amarnath, J., International Review on Modelling and Simulations , 4, 1799 (2011)

22. Nirmala Devi, G., Chitra, S., Selvasekarapandian, S., Premalatha, M., Monisha, S., Saranya, J., 23, 3377 (2017)

23. Rajagiri, A.K., Mn, S.R., Nawaz, S.S., Suresh Kumar, T. E3S Web of Conferences, 87, (2019) 